\title{
Paediatric neuro-imaging
}

\section{S Misser}

Lake Smit and Partners, Durban

S Misser, MB ChB, FCRad (D) SA

Corresponding author: S Misser (misser@lakesmit.co.za)

A 2-year-old boy presented with microcephaly and developmental delay. Below are the MRI images obtained. Describe the relevant findings and provide the most appropriate clinical diagnosis. Please submit your response to Dr Misser at misser@lakesmit. co.za not later than 3 May 2013. The winning respondent will receive a R1 000 award from the RSSA. A detailed diagnosis and discussion will be presented in the next issue of the SAJR.

S Afr J Rad 2013;17(1):45. DOI:10.7196/ SAJR.843

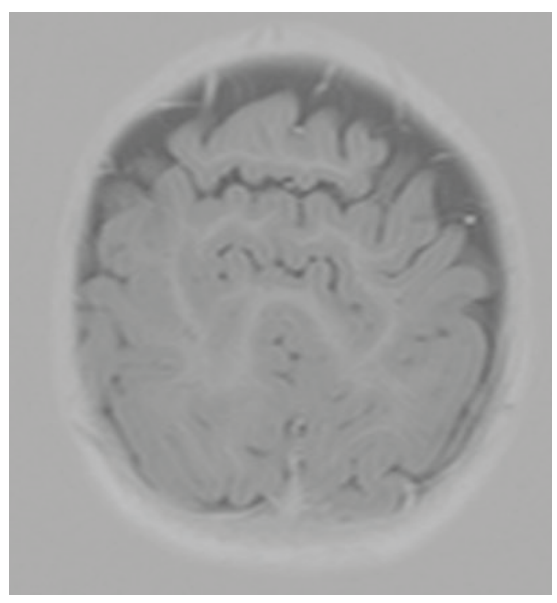

Fig. 3. Axial inversion recovery image of frontal lobes.

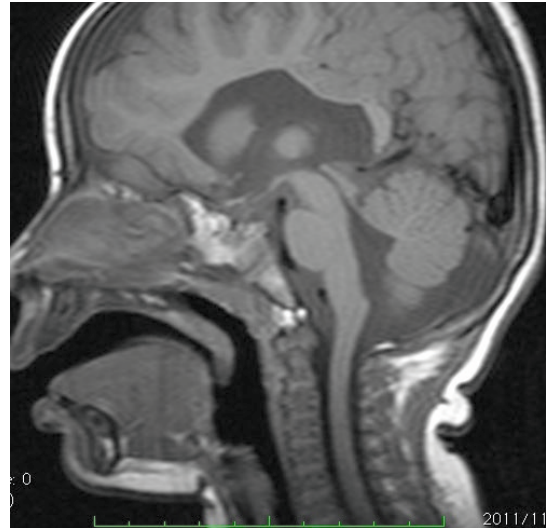

Fig. 1. Sagittal T1-weighted midline MR image.

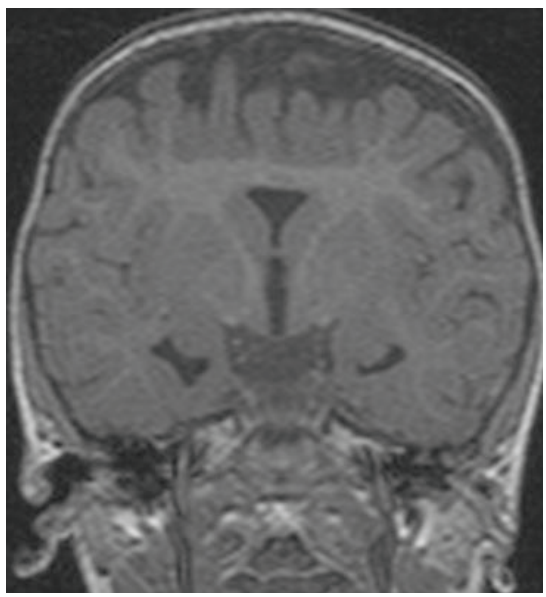

Fig. 4. Coronal T1 image at level of the third ventricle.

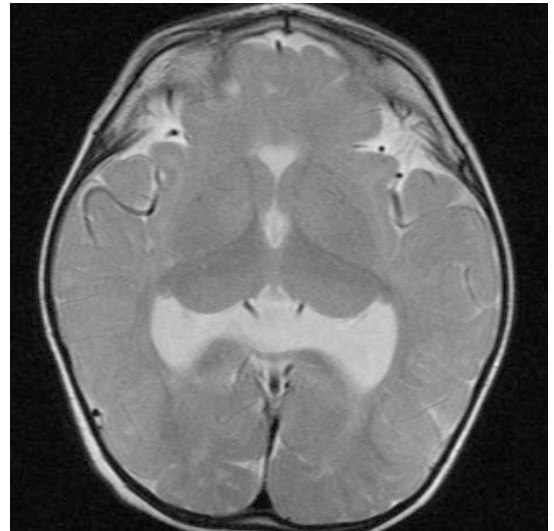

Fig. 2. Axial T2-weighted image at level of thalami.

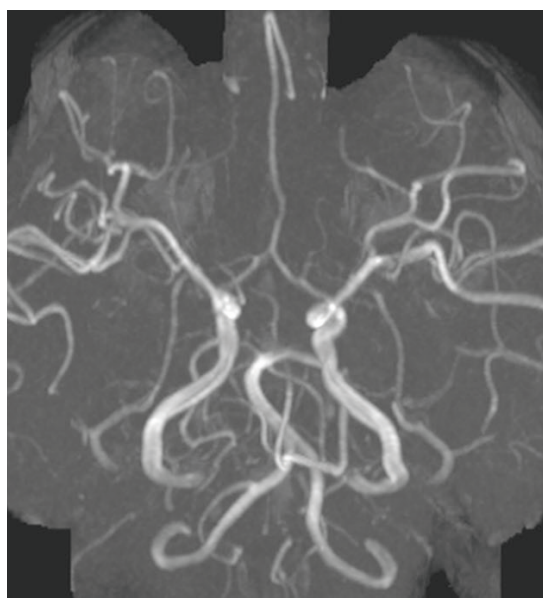

Fig. 5. TOF MRA of Circle of Willis and intracranial circulation. 